\title{
Adherence to COPD guidelines in general practice: impact of an educational programme delivered on location in Danish general practices
}

\author{
*Charlotte Suppli Ulrik', Tina Brandt Sørensen², Torben Brunse Højmark³, \\ Kim Rose Olsen ${ }^{4}$, Peter Vedsted ${ }^{3}$
}

\author{
1 Respiratory Section, Internal Medicine Unit, Hvidovre University Hospital, Hvidovre, Denmark \\ 2 Department of Pulmonary Medicine, Regional Hospital of Horsens, Horsens, Denmark \\ ${ }^{3}$ Lege Artis Consult Aps, Aarhus, Denmark \\ ${ }^{4}$ GSK AS, Brøndby, Denmark
}

Originally received 23rd March 2012; resubmitted 22nd May 2012; revised 12th July 2012; accepted 17th August 2012; online 16th October 2012

\begin{abstract}
Background: The general practitioner (GP) is often the first healthcare contact for patients with chronic obstructive pulmonary disease (COPD).

Aims: To determine whether participating in a standardised educational programme delivered in the GP's own practice is associated with adherence to COPD guidelines.

Methods: A nationwide register-based observational before and after study was undertaken with a control group of propensity-matched practices (follow-up period 6 months). COPD was defined as age 40+ years and at least two prescriptions for inhaled medication. The educational programme consisted of a 3-hr teaching lesson with a respiratory specialist and five visits by a representative from the sponsoring pharmaceutical company focusing on assessment and management of patients including written algorithms. A one-to-one propensity-matched control group of practices was selected. Register data were used to compare the rate of spirometry testing, preventive consultations, and influenza vaccinations provided to COPD patients and the rate of spirometry testing in non-COPD individuals, assumed to reflect diagnostic activity.

Results: Data for 102 participating GP practices were analysed. Participating clinics had a significant increase in preventive consultations and influenza vaccinations $(p<0.05)$. For the control group, a significant change was observed only for influenza vaccinations. No significant change was found when comparing participating and control clinics in the difference-in-difference estimator. However, a significant improvement was observed for the subgroup of 48 clinics with the lowest starting point of spirometry testing.

Conclusions: Focused education of GPs and their staff delivered in the GPs' own practices may improve adherence to COPD guidelines, not least for clinics with a high potential for improvement.

(C) 2013 Primary Care Respiratory Society UK. All rights reserved.

CS Ulrik et al. Prim Care Respir J 2013; 22(1): 23-28

http://dx.doi.org/10.4104/pcrj.2012.00089
\end{abstract}

Keywords COPD, guidelines, general practice, adherence, spirometry, follow-up visits

\section{See linked editorial by Tomlins on pg 6}

\section{Introduction}

Chronic obstructive pulmonary disease (COPD) represents a major and increasing - health problem in most parts of the world. In Denmark, COPD is the fourth most frequent cause of death with approximately 3,200 deaths per year. ${ }^{1}$ Based on data from the
Copenhagen City Heart Study, Løkke et al. ${ }^{2}$ have estimated that close to 270,000 Danish people have clinically significant COPD out of a population of 5.5 million inhabitants.

The first Danish guidelines addressing the diagnosis and management of COPD, primarily aimed at general practice, were published in 1998. ${ }^{3}$ In 2007 the Danish National Board of Health ${ }^{4}$ published national recommendations for the early detection and

\footnotetext{
* Corresponding author: Dr Charlotte Suppli Ulrik, Respiratory Section, Internal Medicine Unit, Hvidovre University Hospital, Hvidovre 2650, Denmark. Tel: +45 21623648 E-mail: csulrik@dadlnet.dk
} 
management of COPD and, in 2008, the Danish College of General Practitioners ${ }^{5}$ published, with specialists in respiratory medicine as members of the Working Group, their guidelines for the diagnosis, treatment, surveillance, and rehabilitation of patients with COPD. However, in Denmark, as in most countries, we have only very limited information regarding the level of adherence to COPD guidelines.

COPD is widely accepted as a preventable and treatable disease, ${ }^{6}$ but unfortunately a substantial proportion of patients is diagnosed in advanced stages of the disease. ${ }^{6.7}$ More focus on diagnosis, staging and management - including smoking cessation programmes and pharmacological treatment - may therefore reduce the overall burden of COPD ${ }^{6.8}$ In most cases the general practitioner (GP) represents the first point of contact with the healthcare system as well as the coordinating healthcare professional for a patient with COPD. Therefore, in order to improve early detection of COPD and care of patients diagnosed with COPD, it is of utmost importance to ensure optimal knowledge and skills related to diagnosing and managing COPD in general practice.

In previous studies from Denmark, Lange et al. ${ }^{9}$ and Ulrik et al..$^{10}$ have shown that participation by GPs in an educational programme enhances the use of spirometry for diagnosis and assessment of COPD. These studies have also observed a positive effect with regard to smoking cessation advice, grading of dyspnoea, and referral for rehabilitation. However, we still need to know the impact of education of GPs and their staff on adherence to COPD guidelines with regard to early detection and, for patients already diagnosed with COPD, the number of spirometry tests, annual control consultations, and provision of influenza vaccination. As in the previously published studies from Denmark, ${ }^{9,10}$ COPD was defined on the basis of age and prescriptions for inhaled medication.

The aim of this study was to assess whether participating in an extensive educational programme for GPs and their staff had an impact on adherence to specific parts of the national COPD guidelines (spirometry testing, preventive consultations, and influenza vaccinations), primarily with regard to early detection of the disease and follow-up of patients treated for COPD.

\section{Methods}

\section{IDA educational programme}

The study was part of the IDA project (acronym for implementing the national COPD guidelines in general practice). All educational activities in the IDA programme took place in the participating GP's own consultation. The IDA educational programme consisted of a 3hr teaching lesson conducted by a specialist in respiratory medicine with COPD as his/her primary area of expertise. Furthermore, practices were offered up to five visits by a representative from the sponsoring pharmaceutical company (GSK) providing extensive help especially with regard to coding of patients, spirometry technique, and training of device technique. Written educational material, including algorithms for assessment and treatment, were also provided to all participating GPs and their staff.

\section{Setting and participating GPs}

Almost all citizens in Denmark ( $\geq 98 \%)$ are registered with a specific general practice with which they must consult for medical advice, and the GPs therefore act as gatekeepers to most other parts of the healthcare system. The IDA educational programme is still ongoing (completed in 2013), but only GP clinics completing their participation in the programme (i.e. IDA I and IDA II) by the end of 2010 were included in the present analysis. The only difference between IDA I and IDA I| was the timing of the intervention. To be included in the intervention group at least one GP and one practice nurse from each practice had to attend and complete the IDA training programme. Furthermore, information had to be available regarding initiation and end date of the participation in the IDA educational programme. All participants included in the present analysis attended the training programme in the period 2008-2010.

\section{Definition of COPD}

In Denmark all citizens are registered with a unique personal identifier (CPR number). All registers and individual data can be linked by this number.

In the present study, individuals with COPD were defined as follows: (1) 40+ years of age; and (2) at least two prescriptions in the year 2007 for a drug in the following two ATC groups: ATC code R03A (adrenergics for inhalation) and/or ATC code R03B (other drugs for obstructive lung disease, inhalation).

Data on redeemed medicine was collected from the National Register of Medicinal Product Statistics. Individuals fulfilling the abovementioned criteria are referred to as the COPD study cohort. This definition of COPD was based solely on age and chronic use of medicine indicated for obstructive lung diseases, and thus not in accordance with the GOLD guidelines. However, it takes advantage of the fact that prescribing data are always recorded and allows comparison with previous Danish studies using comparable algorithms. ${ }^{910}$

\section{Data collection}

In total, $171 \mathrm{GP}$ clinics participated in IDA I and II. For seven and 78 participating clinics, respectively, the starting or end date of the IDA education programme was missing. We therefore used the mean duration of the IDA educational programme (5.2 months for IDA I and 8.1 months for IDA II) to estimate the missing dates. However, 69 GP clinics finished their participation in the IDA educational programme too late in 2010 to allow collection of data on the specified outcome variables. Thus, a total of $102 \mathrm{GP}$ clinics that completed the IDA educational programme could be included in the analysis.

Nationwide, a total of 174,290 individuals fulfilled the COPD inclusion criteria in 2007 , of whom $58 \%$ were women.

\section{Outcome variables}

Information on services provided by the GPs during the period 2008-2010 was retrieved from the Danish National Health Insurance Service Register, including date of delivery. The following COPD relevant indicators were defined as outcome variables: (1) preventive consultations per study cohort patient; (2) spirometry tests per study cohort patient; (3) influenza vaccinations per study cohort patient; and (4) spirometry tests per individual (aged $40+$ years) not meeting our criteria for entry into the study cohort at baseline (2008). The outcome measures were presented as mean rates for the IDA practices and controls. 


\section{Reference group}

In order to separate IDA participants from all other GPs in Denmark, IDA data were merged with data from the National Health Insurance Register in 2008-2010. A total of 2,096 GP clinics were identified and 1,925 $(2,096-(102+69))$ could be included in a matched control group. However, it was not possible to identify 45 of the participating IDA GP clinics due to missing ID number and, instead of being included in the group of IDA clinics, these practices may have been matched into the control group and may potentially lead to an underestimation of the impact of the IDA educational programme.

A control group was established for the entire group of IDA GP clinics and for specified subgroups by nearest neighbour propensity score matching with no replacement. The matching function was defined as list size, number of patients with COPD, and the geographical location (region) of the GP clinic. In order to reduce matching bias we used propensity score calipers defined as 0.2 of the standard deviation of the propensity score. ${ }^{11-13}$

\section{Data analysis}

Initially an overall analysis of the four outcome measures was done including all 102 IDA participants, summarising the outcome measures for each of the clinics 6 months before and after participating in the IDA educational programme and, likewise, data on outcome measures were summarised for the control group. Secondly, subgroup analyses were done for each of the outcome variables including only IDA participants with a baseline below the median value of the total group of 102 IDA participants based on provided services in 2008. It was assumed that IDA GP clinics providing relatively few of the medical services of interest would be most likely to change behaviour after participating in the education programme. Difference-in-difference estimation ${ }^{14}$ was used to assess the impact of the IDA educational programme on the volume of each of the outcome variables, and the estimates were tested for statistical significance using dummy ordinary least square regression. By using the difference-in-difference method we firstly estimate the change in outcome measures before and after the intervention for both the intervention and control group, and secondly, we estimate the effect of the intervention as the difference between the intervention and the control group, thus difference-in-difference estimation. A p value of $\leq 0.05$ was regarded as statistically significant.

The study was approved according to the Danish law for research registers by the Danish Data Protection Agency (Jr. No. 2010-41-5665).

\section{Results}

The characteristics of the 1,925 GPs not enrolled in the IDA educational programme, the 102 IDA GP clinics, and the GPs in the matched control group are given in Table 1. It is evident from Table 1 that large practices with a high number of patients and the three geographical regions not comprising the two largest cities in Denmark were overrepresented in the IDA group. However, Table 1 shows that the matching procedure had, to a large extent, controlled for potential bias in the IDA group.

In general, the 102 IDA GP clinics had a more positive increasing trend with regard to the outcome measures than GPs not enrolled in the IDA educational programme (Table 2). Apart from the number of influenza vaccinations, as expected the IDA group was already at baseline (2008) at a higher level than the non-IDA GP clinics with regard to the three other outcome variables (Table 2). The IDA GPS almost doubled the number of preventive consultations, spirometry tests in study cohort patients, influenza vaccinations, and spirometry tests in non-COPD patients from 2008 to 2010 compared with the non-IDA participants (Table 2 ).

The results of the difference-in-difference estimation are given in Table 3. None of the difference-in-difference estimators was statistically significant at the $5 \%$ level. However, a significant increase in preventive consultations $(p=0.009)$ and influenza

Table 1. Characteristics of all non-IDA GPs, the intervention (IDA educational programme; IDA GP clinics) group, and the matched control group according to number of study cohort patients, total number of patients, and geographical area

\begin{tabular}{|c|c|c|c|c|c|c|c|c|}
\hline GP group & Statistic & $\begin{array}{l}\text { Study } \\
\text { cohort } \\
\text { list size } \\
2007\end{array}$ & $\begin{array}{l}\text { List } \\
\text { size } \\
2008\end{array}$ & $\begin{array}{l}\text { North } \\
\text { Denmark } \\
\text { Region }\end{array}$ & $\begin{array}{l}\text { Central } \\
\text { Denmark } \\
\text { Region }\end{array}$ & $\begin{array}{l}\text { Region } \\
\text { of } \\
\text { Southern } \\
\text { Denmark }\end{array}$ & $\begin{array}{l}\text { Capital } \\
\text { Region } \\
\text { of } \\
\text { Denmark }\end{array}$ & $\begin{array}{l}\text { Region } \\
\text { Sealand }\end{array}$ \\
\hline \multirow{2}{*}{ All $(n=1925)$} & Mean & 66 & 2,426 & $9 \%$ & $22 \%$ & $18 \%$ & $38 \%$ & $13 \%$ \\
\hline & Maximum & 383 & 14,985 & & & & & \\
\hline IDA GP clinics $(n=101)$ & Maximum & 304 & 9,597 & & & & & \\
\hline \multirow[t]{3}{*}{ Matched controls $(n=101)$} & Minimum & 18 & 1,039 & & & & & \\
\hline & Mean & 112 & 3,866 & $21 \%$ & $13 \%$ & $42 \%$ & $6 \%$ & $19 \%$ \\
\hline & Maximum & 266 & 9,621 & & & & & \\
\hline
\end{tabular}

*One IDA GP was excluded from this analysis because no control GP could be found within the defined propensity score interval. 


\begin{tabular}{|c|c|c|c|c|}
\hline Outcome variable & & 2008 ** & $2009 * *$ & 2010 ** \\
\hline \multirow{4}{*}{$\begin{array}{l}\text { Annual mean number of preventive consultations per study } \\
\text { cohort COPD patient }\end{array}$} & Non-IDA GPs & 0.460 & 0.502 & 0.552 \\
\hline & IDA GP clinics & 0.623 & 0.814 & 1.046 \\
\hline & $\mathrm{p}$ value* & $<0.01$ & $<0.01$ & $<0.01$ \\
\hline & Total & 0.468 & 0.517 & 0.577 \\
\hline \multirow{4}{*}{$\begin{array}{l}\text { Annual mean number of spirometry tests per study } \\
\text { cohort COPD patient }\end{array}$} & Non-IDA GPs & 0.229 & 0.212 & 0.219 \\
\hline & IDA GP clinics & 0.297 & 0.353 & 0.405 \\
\hline & $p$ value* & 0.011 & $<0.01$ & $<0.01$ \\
\hline & Total & 0.233 & 0.219 & 0.228 \\
\hline \multirow{4}{*}{$\begin{array}{l}\text { Annual mean number of influenza vaccinations per study } \\
\text { cohort COPD patient }\end{array}$} & Non-IDA GPs & 0.069 & 0.110 & 0.096 \\
\hline & IDA GP clinics & 0.067 & 0.121 & 0.112 \\
\hline & $p$ value* & 0.69 & 0.19 & 0.05 \\
\hline & Total & 0.069 & 0.111 & 0.097 \\
\hline \multirow{4}{*}{$\begin{array}{l}\text { Annual mean number of spirometry tests per non-COPD } \\
\text { patient aged } 40+\text { years }\end{array}$} & Non-IDA GPs & 0.015 & 0.016 & 0.017 \\
\hline & IDA GP clinics & 0.019 & 0.024 & 0.030 \\
\hline & $p$ value* & 0.03 & $<0.01$ & $<0.01$ \\
\hline & Total & 0.016 & 0.016 & 0.018 \\
\hline
\end{tabular}

*IDA vs. non-IDA practices. ** Rate per person, e.g. mean number of preventive consultations for non-IDA GPs in 2008 of 0.46 means that 4.6 of 10 individuals had a preventive consultation that year.

Table 3. Difference-in-difference estimates for the full sample $(n=202,101+101)$ with regard to preventive consultations, spirometry testing, influenza vaccinations, and spirometry tests in individuals not defined as having COPD

\begin{tabular}{|c|c|c|c|c|c|}
\hline & & Before & After & Difference & $\mathrm{p}$ value \\
\hline \multirow{3}{*}{$\begin{array}{l}\text { Preventive consultations per study } \\
\text { cohort list size }\end{array}$} & Intervention & 0.362 & 0.475 & 0.113 & $0.009 *$ \\
\hline & Matched control & 0.263 & 0.305 & 0.042 & 0.338 \\
\hline & Difference-in-difference & & & 0.071 & 0.248 \\
\hline \multirow{3}{*}{$\begin{array}{l}\text { Spirometry testing per study cohort } \\
\text { list size }\end{array}$} & Intervention & 0.155 & 0.188 & 0.033 & 0.076 \\
\hline & Matched control & 0.110 & 0.118 & 0.008 & 0.624 \\
\hline & Difference-in-difference & & & 0.025 & 0.292 \\
\hline \multirow{3}{*}{$\begin{array}{l}\text { Influenza vaccinations per study cohort } \\
\text { list size }\end{array}$} & Intervention & 0.056 & 0.104 & 0.048 & $<0.001^{*}$ \\
\hline & Matched control & 0.059 & 0.096 & 0.037 & $<0.001^{*}$ \\
\hline & Difference-in-difference & & & 0.011 & 0.349 \\
\hline \multirow{3}{*}{$\begin{array}{l}40+\text { Non-COPD patient spirometry } \\
\text { testing per } 40+\text { non-COPD list size }\end{array}$} & Intervention & 0.009 & 0.011 & 0.002 & 0.127 \\
\hline & Matched control & 0.008 & 0.008 & 0.001 & 0.521 \\
\hline & Difference-in-difference & & & 0.001 & 0.376 \\
\hline
\end{tabular}

vaccinations $(p<0.001)$ was observed for the intervention group after participating in the educational programme.

Table 4 shows the results of the difference-in-difference estimation of a subsample of 48 IDA GP clinics with a baseline value of the outcome variables of interest below the median. For this subsample of IDA clinics a significant difference-in-difference estimator was found for the number of spirometry tests.

\section{Discussion}

\section{Main findings}

In the present study we were only able to show a significant impact of the educational programme on the number of spirometry tests for a subgroup of participating clinics with a high potential for improvement. However, although not significant, the present study showed a clear trend that participating in an extensive educational programme on COPD in general practice had an impact on adherence to COPD guidelines, assessed as the number of preventive consultations, spirometry tests, and influenza vaccinations provided in general practice for patients included in the study cohort compared with the development in the matched control group. Furthermore, our study also revealed an increase in the number of spirometry tests for non-COPD patients aged $40+$ years, probably reflecting more 
Table 4. Difference-in-difference estimates for a subsample of IDA clinics with baseline outcome values below the sample median $(n=96,48+48)$

\begin{tabular}{|c|c|c|c|c|c|}
\hline & & Before & After & Difference & $\mathrm{p}$ value \\
\hline \multirow{2}{*}{$\begin{array}{l}\text { Preventive consultations per study } \\
\text { cohort list size }\end{array}$} & Intervention & 0.201 & 0.341 & 0.140 & $0.020 *$ \\
\hline & Matched control & 0.093 & 0.138 & 0.045 & $0.003^{*}$ \\
\hline \multirow{3}{*}{$\begin{array}{l}\text { Spirometry testing per study cohort } \\
\text { list size }\end{array}$} & Intervention & 0.085 & 0.142 & 0.057 & $0.007^{*}$ \\
\hline & Matched control & 0.040 & 0.051 & 0.011 & 0.202 \\
\hline & Difference-in-difference & & & 0.045 & $0.045^{*}$ \\
\hline \multirow{2}{*}{$\begin{array}{l}\text { Influenza vaccinations per study cohort } \\
\text { list size }\end{array}$} & Matched control & 0.035 & 0.075 & 0.040 & $<0.001^{*}$ \\
\hline & Difference-in-difference & & & 0.014 & 0.289 \\
\hline \multirow{3}{*}{$\begin{array}{l}40+\text { Non-COPD patient spirometry } \\
\text { testing per } 40+\text { non-COPD list size }\end{array}$} & Intervention & 0.007 & 0.011 & 0.004 & 0.059 \\
\hline & Matched control & 0.004 & 0.004 & 0.000 & 0.715 \\
\hline & Difference-in-difference & & & 0.004 & 0.094 \\
\hline
\end{tabular}

focus on early detection of COPD. This increase was seen especially in those GP practices participating in the educational programme providing the medical services of interest below the median value at baseline, although this was statistically significant only for the number of spirometry tests.

In the present study COPD was defined on the basis of prescription of inhaled medication indicated for COPD and age 40+ years. We have therefore probably included some patients who had asthma and not COPD, and possibly also individuals treated for COPD who have never been formally diagnosed with the disease and/or individuals reporting COPD-like symptoms due, for instance, to heart failure or obesity. The previously published KVASIMODO ॥ study ${ }^{10}$ revealed that the treatment regimen for the majority of COPD patients treated by their GP included inhaled corticosteroids, irrespective of disease severity. This definition of COPD was chosen because one of the major obstacles for adherence to COPD guidelines - and probably also asthma guidelines - in general practice is difficulties in using spirometry, not least with regard to interpretation of results, ${ }^{15}$ and by that a highly relevant marker for improvement in adherence to guidelines. Using this definition has the advantage that we identified a group of individuals actually treated by their GP who provided them with at least two prescriptions for a drug indicated for obstructive lung disease in 2007. Furthermore, as we compared them with a matched control group, we believe that the observed increases in the outcome measures can be interpreted as resulting from the educational programme. It might, however, be partly due to spill-over effects from asthma patients, but as this is likely to make the estimation of the effect of the educational programme for patients with COPD rather conservative, we believe that the methodology used is appropriate.

\section{Interpretation of findings in relation to previously published work}

Our study confirms the findings of previously published studies s, $^{90}$ but, in contrast to those studies, all educational activities related to the IDA programme took place in each of the participating GPs' practice. The 3-hr teaching lesson with a specialist in respiratory medicine in the GP's practice with only the GP and his/her clinic staff present offered an excellent opportunity to ask questions, discuss clinical cases, and perform spirometry tests under supervision of a specialist. Furthermore, as all participating practices were offered up to five visits by a skilled representative from the sponsoring pharmaceutical company, providing extensive guidance with regard to spirometry technique, training of device technique, and educational material including algorithms for assessment and treatment of patients with COPD, the complete IDA educational programme offered a unique opportunity for improving skills and knowledge related to COPD. It is therefore likely that the IDA educational programme has been more successful in recruiting and retaining GPs with a relatively low interest in COPD. Improvement in adherence to COPD guidelines, including both diagnosis and management, among GPs is of the utmost importance in order to reduce the overall burden of $\mathrm{COPD}^{6,8}$ as well as annual consultations including spirometry in accordance with the Danish COPD guidelines developed by the Danish society for General Practitioners. ${ }^{5}$ Although the present strategy for promoting adherence to COPD guidelines is demanding both in time and resources, it may provide us with a successful way forward in other countries also, although further studies are needed to test the effect of the produced changes on health outcome.

\section{Strengths and limitations of this study}

The present study had a high statistical precision and a large number of included individuals. The before-and-after design with an untreated comparison group combined with the construction of a control group using propensity score matching reduces the threats of internal validity compared with a simple one group before-and-after design. We believe our design deals to a large extent with the potential problems of omitted variables (i.e. events affecting the outcome measures other than the IDA programme such as seasonal variation). However, the matching function does not include general practice characteristics such as physicians' professional interests. One 
can argue that physicians with a professional interest in COPD are fully up to date with present clinical practice and are therefore less likely to be affected by the IDA programme. If these general practices are either less or more likely to participate in the IDA programme, the difference-in-difference estimates may be either over- or underestimated.

\section{Conclusions}

We conclude that adherence to COPD guidelines in general practice as reflected by the number of spirometry tests, preventive consultations, and influenza vaccinations - may be improved, not least in clinics with a high potential for improvement, by offering an extensive educational programme to the GPs and their staff delivered in the GP's own practice. Future studies should assess if longer followup periods affect the results and examine whether better adherence leads to improvement in quality of care and prognosis for COPD patients.

Handling editor Niels Chavannes

Statistical review Gopal Netuveli

Acknowledgements The authors wish to thank all participating GPs and their staff for taking part in the IDA educational programme.

Conflicts of interest The authors declare that they have no conflicts of interest in relation to this article.

Contributorship As principal investigators, CSU, TBS, TBH, KRO and PV participated in the planning of the study. They had full access to the study data and take responsibility for their integrity and the accuracy of their analysis. CSU and KRO drafted the manuscript, and the report was revised for important intellectual content by TBS and PV. TBH analysed the data and provided the statistical expertise. Funding This study was, as well as the IDA educational programme, sponsored by GSK Denmark.

\section{References}

1. Statistics Denmark. www.dst.dk (accessed May 2012)

2. Løkke A, Lange $P$, Scharling $H$, Fabricius $P$, Vestbo J. Developing COPD: a 25 year follow-up study of the general population. Thorax 2006;61:935-9. http://dx.doi.org/10.1136/thx.2006.062802

3. Lange $P$, Hansen JG, Iversen $M$, et al. Diagnosis and treatment of COPD. Ugeskr Laeg 1998;Suppl.1:1-39.

4. Danish National Board of Health. KOL: Anbefalinger for tidlig opsporing, opfølgning, behandling, og rehabilitering (COPD: Recommendations for early detection, monitoring, treatment and rehabilitation; in Danish).

5. Nielsen LM, Brorson S, Gorlen T, et al. KOL i Almen Praksis (COPD in General Practice; in Danish). Danish College of General Practitioners, 2008.

6. Global Initiative for Chronic Obstructive Lung Disease. Global Strategy for Diagnosis, Management and Prevention of COPD. www.goldcopd.com (accessed February 2012).

7. Juel K, Døssing M. COPD in Denmark (in Danish). Statens Institut for Folkesundhed, 2003.

8. National Institute for Health and Clinical Excellence. Management of COPD in adults in primary and secondary care (CG101). Guidance.nice.org.uk/CG101 (accessed Nov 2011).

9. Lange $\mathrm{P}$, Rasmusen FV, Borgeskov $\mathrm{H}$, et al. The quality of COPD care in general practice in Denmark: the KVASIMODO study. Prim Care Respir J 2007;16:174-81. http://dx.doi.org/10.3132/pcrj.2007.00030

10. Ulrik CS, Hansen EF, Jensen MS, et al. Management of COPD in general practice in Denmark: participating in an educational program substantially improves adherence to guidelines. Int J COPD 2010;5:73-9. http://dx.doi.org/10.2147/COPD.S9102

11. Rosenbaum PR, Rubin DB. The central role of the propensity score in observational studies for causal effects. Biometrika 1983;70:41-55. http://dx.doi.org/ 10.1093/biomet/70.1.41

12. Rosenbaum PR, Rubin DB. Constructing a control group using multivariate matched sampling methods that incorporate the propensity score. Am Stat 1985;39:33-8.

13. Austin PC. Optimal caliper widths for propensity-score matching when estimating differences in means and differences in proportions in observational studies. Pharm Stat 2011;10:150-61. http://dx.doi.org/10.1002/pst.433

14. Meyer BD. Natural and quasi-experiments in economics. I Buss Econom Stat 1995;13:151-6.

15. Jones RC, Dickson-Spillmann M, Mather MJ, Marks D, Schackell BS. Accuracy of diagnostic registers and management of chronic obstructive pulmonary disease: the Devon primary care audit. Respir Res 2008;9:62. http://dx.doi.org/10.1186/14659921-9-62

\section{Available online at http://www.thepcrj.org}

